\title{
REDES SOCIAIS E TEORIA SOCIAL: REVENDO OS FUNDAMENTOS DO CONCEITO
}

\section{Sonia Acioli}

\section{Resumo}

Este artigo discute os vários usos e abordagens utilizadas em relação à expressão redes sociais, que tem sido naturalizada e associada apenas às tecnologias da informação. É um estudo conceitual que pretende situar historicamente a noção de redes, buscando ainda identificar as formas as quais a expressão redes sociais tem sido articulada e as abordagens empreendidas. Para tal, foi realizada uma revisão bibliográfica tendo como base os campos da Sociologia, Antropologia, Informação e Comunicação por serem essas as áreas aonde a noção de redes teve sua origem sendo também mais freqüentemente utilizada. Buscando pensar as possibilidades de análise utilizando a noção de rede, esboçamos três possíveis abordagens inspiradas na leitura de Barnes, J. A. e Mitchell, J. Clyde. São elas: uma abordagem metafórica, voltada à filosofia de rede ou ainda a uma aproximação conceitual; uma analítica centrada na metodologia de análise de redes, e, uma tecnológica, cuja preocupação está voltada para as redes de conexões, para as possibilidades que se colocam em relação às interações possíveis na sociedade através de redes eletrônicas, de informações, interorganizacionais. Entendemos que em todas essas abordagens dá-se uma relação direta com a informação, se percebemos informação como processo de troca permanente. Portanto, traba-

\section{INTRODUÇÃO}

Podemos perceber atualmente a naturalização da noção de redes que geralmente se apresenta articulada às tecnologias da informação. Esse que é um debate
Ihar com a idéia de redes significa trabalhar de forma articulada com a idéia de informação. Concluindo, nesse mundo em redes, onde há mais quantidade do que qualidade de informação, a possibilidade de fragmentação de saberes e culturas, e, portanto de sujeitos é muito grande. Nesse sentido, pode-se pensar na relativização dos espaços internos - entendidos como o local - além da valorização desses mesmos espaços, já que as ordens local e global se interpenetram e podem reinventar formas de comunicação e saberes.

\section{Palavras-Chave}

Redes sociais, ciências sociais 
apontar para a necessidade de uma contextualização do termo e de sua utilização.

O presente trabalho tem por objetivo desnaturalizar a noção de redes, situandoa historicamente, buscando ainda identificar os usos aos quais a expressão redes sociais tem sido articulada e as várias abordagens empreendidas.

Falar em redes significa trabalhar com concepções variadas nas quais parecem misturar-se idéias baseadas no senso comum, na experiência cotidiana do mundo globalizado ou ainda em determinado referencial teórico-conceitual. Existe, portanto uma diversidade de definições, que, no entanto parecem conter um núcleo semeIhante relacionado à imagem de fios, maIhas, teias que formam um tecido comum. ${ }^{1}$ Loiola \& Moura (1997, p.54) ressaltam que: "A presença de um ponto central, de uma fonte geradora/ propulsora, não figura no significado popular de rede. A igualdade e a complementaridade entre as partes são seus aspectos básicos, reforçados pela regularidade entre as malhas". ${ }^{2}$

O termo rede sugere ainda fluxo, movimento, indicando uma aproximação com as mais variadas áreas de conhecimento conforme apontamos inicialmente.

\footnotetext{
${ }^{1}$ Segundo Aurélio B. Holanda rede seria o entrelaçamento de fios, cordas, [..] com aberturas regulares fixadas por malhas formando uma espécie de tecido.

${ }^{2}$ A ênfase sugerida pelas palavras em itálico é das próprias autoras.
}

Em Ciências Sociais, rede seria o conjunto de relações sociais entre um conjunto de atores e também entre os próprios atores. Designa ainda os movimentos pouco institucionalizados, reunindo indivíduos ou grupos numa associação cujos limites são variáveis e sujeitos a reinterpretações (COLONOMOS, 1995).

Para a Antropologia Social a noção de redes sociais busca apoiar "a análise e descrição daqueles processos sociais que envolvem conexões que transpassam os limites de grupos e categorias" (BARNES, 1987, p.163).

Sem interesse classificatório, mas buscando pensar as possibilidades de análise utilizando a noção de rede, esboçamos três possíveis abordagens inspiradas na leitura de Barnes, J. A. e Mitchell, J. Cly$\mathrm{de}^{3}$. São elas: uma abordagem metafórica, que estaria voltada à filosofia de rede ou ainda a uma aproximação conceitual; uma analítica centrada na metodologia de análise de redes, e, uma tecnológica, cuja preocupação está voltada para as redes de conexões, para as possibilidades que se colocam em relação às interações possíveis na sociedade através de redes eletrônicas, de informações, interorganizacionais. Ressaltamos ainda que a identificação de abordagens não tem como objetivo criar o-

\footnotetext{
${ }^{3}$ Barnes e Mitchell são antropólogos e parecem ter sido os primeiros a esboçar esse tipo de análise, juntamente com E. Boff.
} 
posições e, sim mostrar a necessidade de complementaridade entre as mesmas.

Entendemos que em todas essas abordagens dá-se uma relação direta com a informação, se percebemos informação como processo de troca permanente.

Como aponta Lévy (1998, p.183):

Se todo processo é interfaceamento, e portanto tradução, é porque nenhuma mensagem se transmite tal qual, em um meio condutor neutro, mas antes deve ultrapassar descontinuidades que a metamorfoseam. A própria mensagem é uma movente descontinuidade sobre um canal e seu efeito será o de produzir outras diferenças.

Portanto, trabalhar com a idéia de redes significa trabalhar de forma articulada com a idéia de informação.

Ao buscarmos retomar as raízes históricas da noção de redes trabalharemos com duas abordagens - a metafórica e a analítica. Posteriormente, tentaremos apresentar alguns autores - anos 80/90 - cujos trabalhos nos parecem se aproximar das abordagens apresentadas, incluindo então a tecnológica.

\section{REDES: UMA BREVE CONTEXTUALI-} ZAÇÃO

A noção de redes / redes sociais nasce na Antropologia Social. A primeira aproximação remonta à Claude Lévi-Strauss em sua análise etnográfica das estruturas elementares de parentesco (década de 40). Em 1940, Radcliffe-Brown usa o termo "redes". Barnes (1972) preocupava-se com a heterogeneidade dos usos da noção de redes, alertando que a idéia de "redes" pudesse tornar-se mais uma palavra da moda, sem definição clara, nem uso específico. Barnes (1972) e Mitchell (1969), referem-se à necessidade de distinguir o uso metafórico do analítico no que se refere às redes.

\subsection{Do Uso Metafórico ao Analítico}

Para Barnes (1972), não existe uma teoria de redes sociais, sendo possível a adaptação da noção de rede à diversas teorias. A concepção básica de redes - tanto para uso metafórico, quanto para o uso analítico - seria a de que a configuração de vínculos interpessoais entrecruzados são de forma inespecífica conectados às ações dessas pessoas e às instituições da sociedade. A idéia que permeia a metáfora de redes, é a de indivíduos em sociedade, ligados por laços sociais, os quais podem ser reforçados ou entrarem em conflito entre si.

A expressão rede social total cunhada por Radcliffe-Brown na década de 50, pretende caracterizar a estrutura social enquanto uma rede de relações institucionalmente controladas ou definidas. Como ressalta Boissevain (1987), para Radcliffe- 
Brown, haveria um pressuposto básico da existência de uma estrutura social que pudesse ser isolada e comparada com outras estruturas sociais, através do isolamento de relações sociais institucionalmente controladas. Bossivain, em sua crítica ao modelo de Radcliffe, nos adverte quanto à necessidade de observarmos as constantes mudanças a que estão submetidas as relações sociais e a impossibilidade de que sejam apreendidas e descritas somente em termos de normas. Radcliffe parece ter usado a noção de rede numa abordagem metafórica, na medida em que nos remete a uma imagem de interconexão de relações sociais, sem deter-se na especificação das propriedades dessas interconexões. Mitchell (1969) nos indica que como metáfora a noção de rede não permite a percepção de vários aspectos das relações sociais tais como - ausência de ligação, intensidade, status, papel social. A preocupação de Mitchel parece ser a de tensionar as duas possibilidades de uso - o metafórico e o analítico, na medida em que também sugere os limites colocados para 0 uso analítico de redes que limitaria a representação de pessoas em "nós" de uma rede, e os relacionamentos entre eles em "linhas" ou "elos". Nesse sentido, o mesmo autor lembra que a noção de redes sociais como método de análise deve ser usada de modo complementar a outros métodos da Sociologia e da Antropologia.

\subsection{Do Uso Analítico ao Metafórico}

Segundo Mitchel (1969), Barnes introduz a idéia de redes sociais como recurso de análise por volta de $1954^{4}$. RadcliffeBrown numa abordagem sociocêntrica percebe a rede social como uma rede na qual todos os membros da sociedade ou parte da sociedade estão imersos (BARNES, 1972). Para Barnes, a metáfora apresentada por Radcliffe teria sido transformada em estudos operacionais com ênfase no aspecto metodológico das análises das relações sociais. Para esse mesmo autor, teria sido Elizabeth Bott (1971) uma das primeiras antropólogas a usar a idéia de rede enquanto uma ferramenta de análise dos relacionamentos entre pessoas, seus elos pessoais e entre as organizações do contexto em que se inserem. Na metáfora de Radcliffe, a rede social envolve todos os membros da sociedade, que existem independentemente de qualquer investigador. A rede social pode por vezes ter membros mais centrais, ainda assim, essa centralidade seria uma construção da investigação em andamento.

Ao desenvolver uma proposta de análise de redes, Barnes ressalta alguns dos critérios de análise: tamanho da rede, ou seja, o número de unidades na rede; aten-

\footnotetext{
${ }^{4}$ Nesse momento na Antropologia, a ênfase eram as análises estruturalistas representadas pelos trabalhos de Evans-Pritchard e Fortes (décadas de 40/50).
} 
ção dada aos efeitos em "A" da relação entre "B" e "C"; se o estudo é sobre questões relacionadas à contatos indiretos ou a categorias / questões individuais.

Radcliffe refere-se à uma rede total que contém todos os laços sociais existentes - no entanto, a maior parte dos estudos lidam com redes parciais - que contém apenas elos sociais de um tipo específico.

Uma questão importante na análise de redes é a identificação de cliques ${ }^{5}$ e o estudo de sua organização em grupos, como também a possibilidade de que sejam elos importantes na troca de determinado tipo de informações.

Esses estudos têm como ponto de partida analisar a realidade social a partir das relações sociais, e não a partir dos atributos dos indivíduos. Nesse sentido, as unidades numa rede podem não ser necessariamente indivíduos, mas também grupos.

Geralmente as unidades de uma rede são representadas graficamente por pontos, e as relações por linhas. São utilizados gráficos e análises matemáticas ("graphy theory') $)^{6}$, que se usados sem articulação com dados de entrevistas, questionários e

\footnotetext{
${ }^{5}$ Cliques são entendidas como grupos de atores direta e fortemente ligados à todos os outros.

${ }^{6} \mathrm{Na}$ década de 50 Moreno utilizou a teoria dos grafos em sua Sociometria, e mais tarde foi também usada nas abordagens da Psicologia Social. (Scherer-Warren, 1999. p. 22).
}

observação tornam-se insuficientes para uma melhor compreensão da realidade social. A possibilidade de perceber relações mais ou menos simétricas; mais ou menos densas; indicam diferenças nos possíveis canais de informação e conseqüentemente, distintos padrões de comunicação entre os membros da rede.

Em redes que tem um grande número de membros, utiliza-se como estratégia começar a análise por um indivíduo e seus contatos mais diretos. O tamanho da rede é, portanto importante para definirmos a análise, como também a multiplicidade de links, ou seja, de relações existentes, e a qualidade das relações - descontínuas, a importância dos papéis que os indivíduos definem para si mesmos nas relações, sua intensidade, durabilidade, freqüência. Como membro de uma rede, o indivíduo é percebido como uma pluralidade de relações. Para captar essa pluralidade, o estudo de redes tem que se debruçar em entrevistas e observação participante.

A proposta de análise de redes constitui-se, portanto numa ferramenta conceitual, analítica e metodológica, o que ressalta a impossibilidade de desvincularmos as possíveis abordagens a serem utilizadas. 
3 PENSAR EM REDES: OS USOS METAFÓRICO, ANALÍTICO E TECNOLÓGICO

Não pensamos de modo compartimentado, portanto esse esforço em indicar usos da noção de redes deve-se a extrema variedade de formas como essa noção é utilizada. No entanto, esses usos estão imbricados, sendo mais ou menos enfatizados em determinados trabalhos. Dessa forma a metáfora rede é desenvolvida por vários autores dentre os quais citaremos apenas alguns.

Ao refletir a relação indivíduo / sociedade Norbert Elias entende o social, o todo, enquanto um conjunto de relações. "Tais relações são sempre relações em processo, isto é: elas se fazem e desfazem, se constroem, se destroem, se reconstroem" (WAIZBORT, 1999, p.92). Dessa forma, a sociedade pode ser percebida como uma rede de indivíduos em constante relação, sugerindo a idéia da interdependência.

Numa palavra, cada pessoa que passa por outra, como estranhos aparentemente desvinculados na rua, está ligada a outras por laços invisíveis, sejam estes laços de trabalho e propriedade, sejam de instintos e afetos. Os tipos mais díspares de funções tornaram-na dependentes de outrem e tornaram outros dependentes dela. Ela vive, e viveu numa rede de dependências (ELIAS, 1994, p.22).
Sociedade para Elias se constituiria a partir dessa rede de funções / relações desempenhadas pelas pessoas. $O$ autor usa a metáfora da rede para explicitar sua concepção relacional de sociedade.

Para ter uma visão mais detalhada desse tipo de inter-relação, podemos pensar no objeto de que deriva o conceito de rede: a rede de tecido. Nessa rede, muitos fios isolados ligam-se uns aos outros. No entanto, nem a totalidade da rede nem a forma assumida por cada um de seus fios podem ser compreendidas em termos de um único fio, ou mesmo de todos eles, isoladamente considerados; a rede só é compreensível em termos da maneira como eles se ligam, de sua relação recíproca (ELIAS, 1994 p.35).

Mílton Santos articula tanto uma abordagem própria da Geografia, quanto da teoria social. Santos (1996) correlaciona a não homogeneidade dos espaços à não homogeneidade das redes, lembrando que: "Num mesmo subespaço, há uma superposição de redes, que inclui redes principais e redes afluentes ou tributárias, constelações de pontos e traçados de linhas" (SANTOS, 1996, p.214).

Para esse autor, através das redes podemos reconhecer três níveis que articulam o global, o regional e o local. São eles: o nível mundial; o território, país ou Estado; e o lugar - "onde fragmentos de rede ganham uma dimensão única e socialmente concreta" (SANTOS, 1996, p.215). As re- 
des teriam um movimento dialético de oposições, confrontos e alianças - incluindo os sistemas de poder - que interferem em todos os níveis. As redes são virtuais, mas também reais, são técnicas, mas também sociais, portanto são por vezes estáveis, mas também dinâmicas. Elas incluem em si mesmas um movimento social de dinâmicas ao mesmo tempo locais e globais, o que indicaria uma tensão entre forças de globalização e de localização.

Ele ressalta que:

Mediante as redes, há uma criação paralela e eficaz da ordem e da desordem no território, já que as redes integram e desintegram, destroem velhos recortes espaciais e criam outros. Quando ele é visto pelo lado exclusivo da produção da ordem, da integração e da constituição de solidariedades espaciais que interessam a certos agentes, esse fenômeno é como um processo de homogeneização. Sua outra face, a heterogeneização, é ocultada. Mas ela é igualmente presente (SANTOS, 1996, p.222).

O uso analítico de rede ou ainda a metodologia de análise de redes tem sido utilizada especialmente na análise das chamadas redes de movimentos, redes de solidariedade, que são expressões vinculadas à estudos do campo dos movimentos sociais. Esses trabalhos partem da análise de redes utilizada pela Antropologia Social, articulando conhecimentos das Ciências Sociais e da Geografia, como caminho metodológico que facilite a apreensão das interações sociais, espaciais, informais e/ou institucionalizadas e temporais, que se estabelecem nesse campo.

Explicitando essa busca metodológica Scherer-Warren (1996, p.10) ${ }^{7}$ ressalta:

\begin{abstract}
A análise em termos de redes de movimentos implica buscar as formas de articulação entre o local e o global, entre o particular e o universal, entre o uno e o diverso, nas interconexões das identidades dos atores com o pluralismo. Enfim trata-se de buscar os significados dos movimentos sociais num mundo que se apresenta cada vez mais como interdependente, intercomunicativo, no qual surge um número cada vez maior de movimentos de caráter transnacional, como os de direitos humanos, pela paz, ecologistas, feministas, étnicos e outros.
\end{abstract}

Scherer-Warren (1996) ressalta que os estudos que indicam como caminho investigativo a análises de redes nos estudos de ações coletivas, tem apontado para a idéia de que as ações coletivas surgem de redes - que interagem e influenciam-se mutuamente.

Nesse sentido, o reconhecimento dessas redes seria um agente facilitador da compreensão dos processos de mobilização, de formação das redes, como também dos "caminhos" percorridos pela informação nesses movimentos. Dessa forma seriam articuladas várias dimensões de aná-

${ }^{7}$ Scherer-Warren cita vários autores que vem trabaIhando com essa abordagem: Klandermans (1992); Melucci (1966); Ayres (1997) e os brasileiros: Doimo (1995); Silva (1993,1996); Moura (1994). 
lise, de forma complementar, de modo a perpassar os seguintes indicadores: territorialidade e desterritorialização - interação entre os vários espaços comunitários, articulações locais, regionais e nacionais temporalidades históricas; sociabilidade político-ético-cultural - articulação das redes submersas com as redes éticopolíticas.

O uso tecnológico é dos mais discutidos atualmente e nesse campo estamos englobando o núcleo de tecnologias da informação - redes de informações, redes de conexões ou redes temáticas, redes interorganizacionais, ou seja, grupos que utilizam o termo rede no sentido de meio de acesso a informações, contato com grupos ou pessoas através de redes de computadores.

Castells (1999, p.78) ao apresentar o que denomina o paradigma da informação ${ }^{8}$ identifica a lógica de redes como uma das características de qualquer sistema nas novas tecnologias da informação devido à complexidade das interações. Seria a possibilidade de "estruturar" o não - estruturado, preservando a flexibilidade. Nesse sentido a lógica de redes na tecnologia da

${ }^{8} \mathrm{O}$ autor aponta como características desse novo paradigma: são tecnologias para agir sobre a informação; penetrabilidade de seus efeitos; lógica de redes; flexibilidade; convergência de tecnologias específicas para uma sistema altamente integrado (p.77-78). informação teria uma interferência nos fluxos de poder.

Para esse autor: "A presença na rede ou a ausência dela e a dinâmica de cada rede em relação às outras são fontes cruciais de dominação e transformação de nossa sociedade" (CASTELLS, 1999, p.497).

Para Castells, as redes são estruturas abertas com possibilidade de expansão ilimitada, desde que os novos nós compartilhem os mesmos códigos de comunicação. Refere-se, portanto a racionalidade da ordem global, aonde parece não haver a possibilidade de incorporação de outros códigos de comunicação.

As redes temáticas ou de conexão se constroem de forma bastante espontânea, ainda que geralmente estimuladas por uma pessoa ou um grupo. Loiola e Moura (1997) ressaltam que essas redes são estruturas informais que articulam indivíduos que passam a interagir por áreas de interesse, como também podem desenvolver relações afetivas.

As redes interorganizacionais seriam redes institucionais cuja composição é geralmente pré-definida relacionada à determinada política institucional. Seriam, portanto redes com maior grau de formalização. 
Essas possibilidades de trabalho em rede geralmente estão relacionadas a pressupostos de flexibilidade, democratização, menor grau de hierarquização, indicando a ampliação de espaços públicos de negociação. Parece-nos que esses pressupostos devem ser olhados com cuidado, e algumas perguntas básicas devem continuar a ser feita: Quem decide? Quem detém as informações? As redes parecem apagar diferenças, criando uma pseudoigualdade.

\section{ALGUMAS CONSIDERAÇÕES FINAIS}

Como aponta Colonomos (1995), o debate sobre redes no campo das ciências sociais ao iniciar-se traz em seu bojo a oposição entre estruturalismo e individualismo metodológico.

A Sociologia de redes transnacionais aponta uma mudança de paradigma, indicando a relativização dos espaços internos na gênese dos movimentos sociais. Os espaços internos teriam um papel diferente na medida em que sua origem e consolidação estariam referidas aos espaços transnacionais. Essa nova forma de pensar os movimentos sociais estaria criando uma imbricação maior entre espaços internos e espaços externos, a partir das quais se dariam interações que constituiriam a gênese desses movimentos. Esse autor aponta que os estudos de rede ressaltam as alianças e coligações que os atores constroem com o objetivo de consolidação do seu poder.

As redes nascem num espaço informal de relações sociais, mas seus efeitos são visíveis para além desse espaço através das relações com o Estado, a sociedade e de outras instituições representativas. A partir de interações estratégicas se dariam novas perspectivas de análise, ou um novo individualismo metodológico (COLONOMOS, 1995).

Giddens (1991) nos confronta com a questão da modernidade e suas descontinuidades. Ele ressalta na modernidade a reivindicação de que o conhecimento é circular, ou seja, circula dentro e fora do ambiente que descreve.

As tendências globalizantes da modernidade são simultaneamente extensionais e intencionais - elas vinculam os indivíduos a sistemas de grande escala como parte da dialética complexa de mudança nos pólos local e global. Muitos dos fenômenos freqüentemente rotulados como pós-modernos na verdade dizem respeito à experiência de viver num mundo em que a presença e ausência se combinam de maneiras historicamente novas (GIDDENS, 1991, p.175-176).

Podemos, portanto pensar que nesse mundo em redes, onde há mais quantidade do que qualidade de informação, a possibilidade de fragmentação de saberes e culturas, e, portanto de sujeitos é muito grande. 
Nesse sentido, o entrelaçamento entre o local e o global torna-se uma reorganização do tempo e do espaço que pode como diria Giddens, dissolver o sujeito num mundo de signos sem centro. Daí a necessidade de pensar o local e o global de modo articulado, com também as várias formas de valorização dos espaços internos entendidos como os espaços locais.

Rede é, portanto um tema que persiste, transformando-se, incorporando grupos de campos teóricos e até mesmo ideológicos diversos. No entanto, voltando ao pensamento de Barnes, e utilizando uma expressão de Lucien $\mathrm{Sfez}^{9}$ entendemos que o tema redes não deve se tornar mais um daqueles termos "confusionantes", que servem para tudo e não explicam nada.

Esse sentimento de ambigüidade com relação à noção e às realidades das redes é citado por Santos (1996, p.222) que para explicitar esse caráter híbrido cita Latour (1991, p.166-167):

o papel dos mistos é exatamente o de unir as quatro "regiões" criadas como sendo diferentes : o natural, o social, o global, o local, de modo a evitar que "os recursos conceituais se acumulem nos quatro extremos [...] "levando a que "nós, pobres sujeitos-objetos, humildes sociedades-natureza, pequenos locaisglobais, sejamos literalmente esquartejados entre regiões ontológicas que mútuamente se definem e

${ }^{9}$ Lucien Sfez é Professor Titular de Ciência Política da Universidade de Paris I, Pantheón, Sorbonne. entretanto não mais se assemeIham às nossas práticas.

Há, portanto uma ordem global, que impõe sua racionalidade como única, a todos os lugares e especificamente à ordem local. Essas duas ordens ainda que aparentemente opostas, como vimos, são interdependentes, mas indicam lógicas diferentes. A ordem global é associada a uma população esparsa, pautada em escalas superiores, onde a solidariedade é produto da organização, e onde se daria a busca contínua por informação. A ordem local é associada a uma população reunida pelo território, pautada na escala do cotidiano, onde a organização seria produto da solidariedade, e onde se daria a busca por comunicação (SANTOS, 1996, p.272).

No entanto, essas ordens se interpenetram, têm interdependência e podem fazer surgir possibilidades de interações não previstas, novas formas de estruturação da realidade, e conseqüen-temente a reinvenção de formas de comu-nicação de saberes e práticas.

\section{REFERÊNCIAS}

BARNES, J.A. Social Networks. Cambridge: Module 26, p.1-29, 1972.

Redes Sociais e Processo Político. In.: FELDEMAN-BIANCO, Bela (Org.). Antropologia das Sociedades Contemporâneas - Métodos. São Paulo: Global, 1987. 223p. 
CASTELLS, M. Sociedade em rede. São

Paulo: Paz e Terra, 1999. (A Era da informação: Economia, Sociedade e cultura, v.1).

COLONOMOS, A. Emergence d'un objet et perspectives internacionalistes. In.: CHARILLON, F. et al. Sociologie des réseaux transnationaux. Paris: Editions L'Harmattan, 1995. 299p.

ELIAS, N. A sociedade dos indivíduos. Rio de Janeiro: Jorge Zahar, 1994. 201p

GIDDENS, A. As Conseqüências da Modernidade. São Paulo: UNESP, 1991. $177 \mathrm{p}$.

LÉVY, P. As tecnologias da Inteligência: o futuro do pensamento da informática. Rio de Janeiro: Ed34, 1993. 203p.

LOIOLA, E.; MOURA, S. Análise de redes: uma contribuição aos estudos organizacionais. In: FISHER, T. (Org.). Gestão Contemporânea, cidades estratégias e organizações locais. Rio de Janeiro: Fundação Getúlio Vargas, 1997. p.53-68.

MITCHEL, J.C. The Concept and Use of Social Networks. In: Social Networks in Urban Situations: analyses of personal relationships in central African towns. Manchester: Manchester University Press, 1969.

SANTOS, M. A Natureza do espaço: técnica e tempo: razão e emoção. São Paulo: HUCITEC, 1996. p. 308.

SCHERER-WARREN, I. Redes de movimentos sociais. São Paulo: Loyola-Centro, 1996. 143p.

. Cidadania sem fronteiras, ações

coletivas na era da globalização. São PauIo: HUCITEC, 1999.

WAIZBORT, L. (Org.). Dossiê Norbet Elias. São Paulo: EDUSP, 1999. 156p.
Sonia Acioli

Graduação em Enfermagem pela Pontíficia Universidade Católica do Rio de Janeiro (1980), Mestrado em Ciências da Saúde pela Fundação Oswaldo Cruz (1994) e Doutorado em Saúde Coletiva pelo Instituto de Medicina Social da Universidade do Estado do Rio de Janeiro (2003). Atualmente é Professora Adjunta do Depto de Saúde Pública e da PósGraduação em Enfermagem da Faculdade de Enfermagem da UERJ e Procientista da mesma universidade. soacioli@uerj.br

\section{Title}

Social Nets And Social Theory: Reviewing The Concept Bases

\begin{abstract}
This article discusses the various usages and approaches related to the expression "social nets", which has been naturalized and associated only to the information technologies. It is a conceptual study intending to situate historically the notion of nets aiming, in addition, to identify the ways in which the expression social nets has been articulated and the undertaken approaches. To achieve this, a bibliographical revision was accomplished, having the fields of Sociology, Anthropology, Information and Communication as basis, for these were the fields where the notion of nets had its origin, and where this term has been utilized the most. In order to think about the analytical possibilities using the notion of nets, we drew three possible approaches inspired on Barnes, J. A. e Mitchell, J. Clyde. They are: a metaphoric approach, related to net philosophy or even to a conceptual approach; an analytical one, focused on network analysis methodology and a technological one, which concern is on connection nets, for the possibilities related to the possible social interactions through electronic, informational, inter organizational nets. We
\end{abstract}


understand that in all those approaches, there is a direct relation with information, if we consider information as a permanent exchange process. Thus, to work with the idea of nets means to work in an articulated way with the notion of information. Concluding, in this world of nets, where there is more amount than quality of information, the possibility of culture and knowledge and, thus, subjects fragmentation is very big. In this sense, we may think about making the internal spaces - considered as the place - relative, besides the valorization of those spaces, whereas the local and global orders interpenetrate and they can reinvent ways of communication and knowledge.

\section{Keywords}

Social nets, social sciences

\section{Título}

Redes Sociales y Teoría Social: Reviendo los fundamentos del concepto

\section{Resumen}

Este artículo discute los varios usos y enfoques utilizados en relación a la expresión Redes sociales, que es naturalizada y asociada solamente a las tecnologías de la información. Es un estudio conceptual que intenta situar históricamente la noción de redes, buscando también identificar las formas a las cuales la expresión redes sociales es articulada y los enfoques emprendidos. Para tanto, fue cumplida una revisión bibliográfica teniendo como base los campos de la Sociología, Antropología, Información y Comunicación porque fue en ellos que la noción de redes tuvo su origen, siendo también más frecuentemente usada. Buscando pensar las posibilidades de análisis usando la noción de red, fueron delineados tres enfoques posibles inspirados en la lectura de Barnes, J.A. y Mitchell, J.C. Son ellos: metafórico, volvido para la filosofía de red o aun para una aproximación conceptual; analítico, centrado en la metodología de análisis de redes; y tecnológico, cuya preocupación está volvida para las redes de conexiones, para las posibilida- desque se colocan en relación a las interacciones posibles en la sociedad a través de redes electrónicas de informaciones entre organizaciones. Se entiende que en todos esos enfoques acaece una relación directa con la información, se percibe información como proceso de cambio permanente. Por lo tanto, trabajar con la idea de redes significa trabajar de manera articulada con la idea de información. Concluyendo, en eso mundo de redes, donde hay más cantitad que calidad de información, la posibilidad de fragmentación de saberes y culturas, y por lo tanto de sujetos, es muy grande. En eso sentido, se puede pensar en la relativización de los espacios internos - entendidos como el local - además de la valorización de esos mismos espacios, ya que las ordinaciones local y global se interpenetran y pueden reinventar formas de comunicación y de saberes.

\section{Palabras Clave}

Red social; ciencia social 